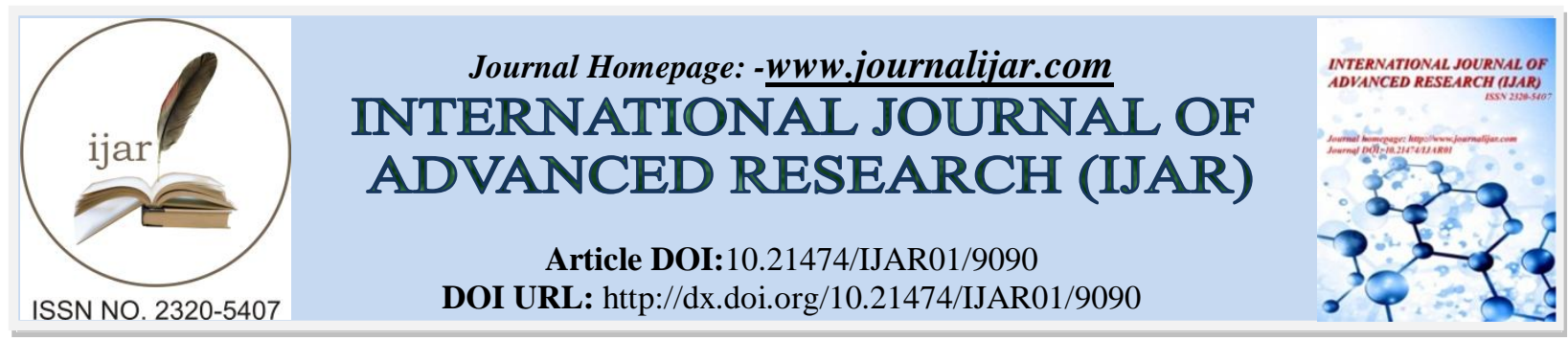

RESEARCH ARTICLE

\title{
USEFULNESS OF NEUTROPHIL ELASTASE AND ENDOGENEOUS PROTEASE INHIBITOR IN ASSESSMENT OF SEVERITY OF PRE-ECLAMPSIA.
}

Dr. Varsha Chowdhry ${ }^{1}$,Dr. Balram Chowdhry ${ }^{2}$ and Dr. G.G Kaushik ${ }^{3}$.

1. MD Assistant Professor, Department of BiochemistryJ.L.N. Medical College \& Attached Group of Hospital, Ajmer, Rajasthan, 305001 India.

2. MD Ex.Sr. Professor \& HOD Department of PediatricsJ.L.N. Medical College \& Hospital, Presently working as Senior Consultant Mittal hospital and research centre Ajmer, Rajasthan, 305001 India.

3. MD Sr Professor \& HOD,Department of Biochemistry J.L.N. Medical College \& Hospital, Ajmer, Rajasthan, 305001 India.

E-Mail drvarsha62@gmail.com

\section{Manuscript Info}

\section{Manuscript History}

Received: 16 March 2019

Final Accepted: 18 April 2019

Published: May 2019

Key words:-

Neutrophil elastase , $\alpha 1$-antitrypsin $(\alpha 1$ $\mathrm{AT})$ and $\alpha 2$-macroglobulin $(\alpha 2-\mathrm{MG})$.
Abstract

Background : (PE) is one of the main causes of maternal and fetal mortality and morbidity. PE is associated with an inflammatory state and with oxidative stress, in maternal circulation. Our aim was to evaluate and compare the levels of oxidative stress and inflammatory markers. Neutrophil Elastase (NE), a serine protease stored in the primary granules of neutrophils, is capable of degrading various extracellular matrix proteins and thus uncontrolled elastase activity can lead to destroyal of the integrity of endothelial cells and could lead to exacerbate the symptoms in preeclampsia.

Aim: The aim of this study was to study usefulness of the activity , of neutrophil elastase and its endogenous inhibitors $\alpha 1$-antitrypsin $(\alpha 1$ AT) and $\alpha 2$-macroglobulin ( $\alpha 2-\mathrm{MG})$ with severity of preeclampsia. Methodology: The present was conducted on 100 subjects, of various age groups. Study included diagnosed pre-eclamptic patients (50) attending Medical OPD, patients admitted in medical and obsetritic \& Gynecological department and patients coming in Radioimmunoassay (RIA) laboratory, Biochemistry Department J.L.N. Medical College \& Hospital, Ajmer. The results of patients were compared with the fifty healthy subjects. Serum CRP was estimated by rapid latex slide and uric acid by uricase method. Plasma elastase was estimated using Succinyl tri- L-alanyl-p-nitroanilide as substrate. Plasma $\alpha 1-A T, \alpha 2-$ MG and PMN elastase/ $\alpha 1$-PI complex were quantified by ELISA. Results: The activity of elastase was increased significantly in severe preeclampsia $(0.72+0.08)$ in comparison to normal $(0.40+0.10)$ and mild preeclamptic subjects $(0.37+0.03)$. The values of $\alpha 1$-AT were significantly less in mild $(83.94+25.08)$ and severe preeclampsia $(68.58+26.39)$ in comparison to normal $(110.26 \neg+42.39)$. There was a significant rise in the levels of $\alpha 2-\mathrm{MG}$ in severe preeclampsia. However, the complex estimation did not evince any significant changes. Serum uric acid and CRP levels significantly elevated in 
preeclampsia compared to controls. Conclusion: Present study indicates that monitoring elevated NE activity is a characteristic marker for severity of preeclampsia. Also, the reduced level of $\alpha 1$-AT is an indication of a possible role of this inhibitor supplementation for the control of complications of preeclampsia ultimately reducing neonatal mortality.

Copy Right, IJAR, 2019,. All rights reserved.

\section{Introduction:-}

Preeclampsia is a condition during pregnancy where there is a sudden rise in blood pressure and swelling, mostly in the face, hands, and feet.Preeclampsia is the most common complication to occur during pregnancy. It generally develops during the third trimester and affects about 1 in 20 pregnancies.If the preeclampsia remains untreated, it can develop to eclampsia, in which the mother can experience convulsions, coma, and can even die. However, complications from preeclampsia are extremely rare if the mother attends her prenatal appointments.

Preeclampsia (PE) is a major cause of maternal and neonatal morbidity and mortality. It is a multisystem disorder which is characterized by vasoconstriction (1), leukocyte activation (2), enhanced inflammatory response (3) and oxidative stress (4). The causes for the development of PE is still unclear and is a topic of active investigation. The pathological lesions of decidual vessels in PE have similarity to atherotic lesions of arteries (5). Neutrophils have been implicated in the pathogenesis of atherotic changes and endothelial dysfunction through release of variety of substances. Elastase is one of such molecules released from neutrophils and is an established marker for neutrophil activation $(6,7,8)$.

Neutrophil Elastase (NE), a serine protease stored in the primary granules of neutrophils, is capable of degrading various extracellular matrix proteins such as elastin, collagen, fibrinogen and proteoglycans (9). Therefore, it can cause vascular basement membrane damage and can facilitate tissue infiltration of neutrophils. Activation of neutrophils is implicated in PE and consequently contributes to vascular basement membrane damage leading to edema and proteinuria (10), a usual observation in PE. A positive correlation have been demonstrated between von Willebrand Factor (a marker of endothelial damage) and NE by Greer et al indicating that neutrophil activation could contribute to endothelial damage and dysfunction in preeclampsia (11).

Thus uncontrolled neutrophil activation can lead to destroyal of the integrity of endothelial cells and could exacerbate the pathophysiological symptoms in PE. It is well established that PE is manifested as mild, moderate and severe forms in pregnant women but it is unclear what exaggerates the symptoms and the severity. This study is an attempt in this direction to correlate the activity of neutrophil elastase and its endogenous inhibitors $\alpha_{1}$-antitrypsin $\left(\alpha_{1}-\mathrm{AT}\right)$ and $\alpha 2$-macroglobulin $\left(\alpha_{2}-\mathrm{MG}\right)$ with severity of PE.

\section{Methodology:-}

The present was conducted on 100 subjects, of various age groups. Study included diagnosed pre-eclamptic patients (50) attending Medical OPD, patients admitted obsetritic \& Gynecological department and patients coming in Radioimmunoassay (RIA) laboratory, Biochemistry Department J.L.N. Medical College \& Hospital, Ajmer. The results of patients were compared with the fifty healthy subjects. Serum CRP was estimated by rapid latex slide and uric acid by uricase method. Plasma elastase was estimated using Succinyl tri- L-alanyl-p-nitroanilide as substrate. Plasma $\alpha 1-\mathrm{AT}, \alpha 2-\mathrm{MG}$ and PMN elastase/ $\alpha 1-\mathrm{PI}$ complex were quantified by ELISA.

50 pregnant normotensive women and 50 preeclamptic pregnant women ( 27 mild and 23 severe cases), were included in the study. All the women were in the age group of 19-36 years and were over 20 weeks of gestation. Normal pregnancy was diagnosed on the basis of clinical and ultrasound evaluation and all of them presented a normal course and outcome of pregnancy. The preeclamptic patients were diagnosed by the presence of hypertension $(>140 \mathrm{mmHg}$ systolic BP and $>90 \mathrm{mmHg}$ diastolic BP) on two occasions with 4-6hours apart, proteinuria (>1+ by urine dipstick method) with or without pathological edema. PE was considered as severe, if the subjects had at least two of the following: $>160 \mathrm{mmHg}$ systolic BP; >110mmHg diastolic BP; dipstick proteinuria of $3+$ or more. All the other cases were considered as mild PE. All patients with any infection, twins, history of 
pregestational diabetes, gestational diabetes mellitus, renal disease, liver disease, cardiovascular disease and hypertension were excluded from the study.

$6 \mathrm{ml}$ of blood was collected from an antecubital vein from all the subjects in tubes containing EDTA (for hematologic studies); Sodium Heparin (for NE, $\alpha_{1}$-AT, $\alpha_{2}$-MG and Polymorphonuclear Elastase/ $\alpha 1$-Proteinase inhibitor complexestimation) and in tubes without anticoagulant (for CRP estimation). Blood samples were centrifuged within 2 hours of collection. After centrifugation, serum and plasma were separated and aliquots were stored at $-70^{\circ} \mathrm{C}$ until assayed. Samples were thawed at room temperature, vortexed and centrifuged before analysis.

\section{Methods:-}

Complete Blood Count was performed by Beckman- Coulter, an automatic blood cell counter.SerumC - reactive protein (CRP) estimation was done by rapid latex slide tests. Serum uric acid was estimated by uricase method (12) . Estimation of plasma elastase was done using Succinyl tri- L-alanyl-p-nitroanilide as substrate at 410nm as per the procedure described by Beith.J, et al (13).Plasma $\alpha_{1}$-AT and $\alpha_{2}$-MGwere analyzed using Enzyme Linked Immunosorbent Assay kit purchased from Immunology Consultants laboratory, Inc, USA.PMN elastase/ $\alpha 1$-PI complex (NE- $\alpha_{1}$-ATcomplex)was quantified by Enzyme Linked Immunosorbent Assay (Calbiochem).

\section{Statistical Analysis:}

The data were statistically analyzed by SPSS software version 22. The results are expressed as Mean+SD. For statistical differences in means between the groups ANOVA (Analysis of variance) was used. $\mathrm{P}$ value $<0.001$ was considered highly significant.

\section{Results:-}

The baseline physical and chemical characteristics of the normal, mild and severe preeclamptic subjects are depicted in Table -1 . The gestational age was in the range of 34 to 37 weeks for normal, and 31 to 36 weeks for mild to severe PE subjects. The blood pressure was elevated significantly in the case of mild and severe cases of PE in comparison to normal. The blood pressure was also significantly higher in severe PE compared to mild PE. The data on proteinuria was suggestive of PE as per the criteria defined. Serum uric acid showed significant rise in preeclampsia group (Mild 7.53+1.35; Severe 8.16+1.57) compared to controls $(4.53+1.30)$. When serum CRP was compared, mild $(12.44+11.40)$ and severe $(14.35+13.98)$ preeclamptic women presented significantly higher CRP levels as compared to normotensive pregnant women.

The data on NE, $\alpha_{1}$-AT, $\alpha_{2}-\mathrm{MG}$ and NE- $\alpha_{1}$-AT complex are presented in Table 2 . The activity of neutrophil elastase was increased two fold in severe preeclampsia $(0.72+0.08)$ in comparison to normal $(0.40+0.10)$ and mild preeclamptic subjects $(0.37+0.03)$ and was statistically highly significant. The values of $\alpha_{1}$-AT have been on the decline and were significantly less in mild and severe PE in comparison to normal; a $60 \%$ reduction in severe and $40 \%$ reduction in mild. There was a significant rise in the levels of $\alpha_{2}-\mathrm{MG}$ in severe preeclamptic women. However, the complex estimation did not evince any significant changes indicating normal balance and did not contribute to analytic value.

\section{Discussion:-}

Preeclampsia exhibits characteristics of an inflammatory disease including neutrophil activation (2, 14, 15). The activation of neutrophils in PE may be due to some pro-inflammatory cytokines and chemoattractants released during an inflammatory response (i.e., TNF- $\alpha$, IL-6 and IL-8) (16). Elastase activity is measured as marker of neutrophil activation in several inflammatory conditions including PE (7, 8, 14, 15). The complications induced by PE state are detrimental to both the mother and the fetus and have been a serious subject of investigation. Research often focuses on the changes in the biochemical parameters with no data on its onset and progress.

The present study was aimed to measure the plasma activity of NE to obtain an insight into the association of this critical parameter with the severity of PE. As anticipated there was a significant association between elastase activity and severity (Fig 1). Our result is in agreement with previous studies conducted (7, 8, 11, 14). This study is supplemented with the measurement of endogenous inhibitors of elastase: $\alpha_{1}$-AT, $\alpha_{2}$-MG as well as $\alpha_{1}$-AT - elastase complex. 
Alpha $_{1}$-antitrypsin inhibits several serine proteases (mainly NE), and adequate activity of this inhibitor is critical for the maintenance of protease -antiprotease homeostasis and the prevention against proteolytic tissue damage (17). Determination of the plasma antiproteolytic activity demonstrates the available level of the inhibitor capable of inhibiting intravascular proteases. Contrary to expectation of an increased levels as response to elevated elastase activity, the levels of $\alpha_{1}$-AT was decreased significantly in preeclamptic cases suggestive of overpowering role of elastase in the complications of PE.

It is also pertinent to note that, there was no increase in the levels of complex in preeclampsia group consequent to the increased elastase activity. This observation indicates decreased synthesis of $\alpha 1-\mathrm{AT}$ rather than its involvement in complex formation to control elastase activity. The reason for decreased $\alpha_{1}$-AT is an area of concern and is suggestive that supplementation of $\alpha_{1}$-AT would be able to minimize the destructive effects of NE on vascular tissues.

We have observed a significantly higher $\alpha_{2}-\mathrm{MG}$ levels in severe PE patients compared with normal or mild PE patients. We expected a reduced $\alpha_{2}-\mathrm{MG}$ concentration in severe $\mathrm{PE}$ as it is expected to bind to elastase and get rapidly cleared from the plasma through macrophage receptors (18). Raised levels is of concern as it opines a decreased receptor-mediated clearance in preeclampsia patients. Moreover, increased levels of this inhibitor in severe PE possibly contribute to the intravascular coagulation as $\alpha_{2}$-MG has antiplasmin activity (19) adding to further severe complications. Horne et al also found high $\alpha_{2}-\mathrm{MG}$ levels in $\mathrm{PE}$ with proteinuria as compared to normal pregnant women (19).

As expected and reported by earlier studies (20,21, 22), a significant increase in the levels of serum uric acid and CRP in preeclampsia compared to controls was observed and points to generalized inflammation in these patients. However, the levels did not yield any information on the severity of the preeclampsia.

\section{Conclusion:-}

Our study concluded that there is significant importance of neutrophil elastase and $\alpha 2 \mathrm{MG}$ to asses the severity of pre-eclampsia The overall result is an indication of a possible role of $\alpha 1$-AT supplementation for the control of complications of preeclampsia.

\section{Acknowledgement:-}

I am highly indebted to the staff \& my colleagues who helped me to accomplish my project.

Conflict of Interest: None declared.

Research funding: None declared.

Table 1:-Baseline characteristics of study groups

\begin{tabular}{|c|c|c|c|c|}
\hline Variables & $\begin{array}{l}\text { Normal Pregnancy } \\
(\mathrm{n}=50)\end{array}$ & $\begin{array}{l}\text { Mild } \\
\text { Preeclampsia } \\
(\mathrm{n}=27)\end{array}$ & $\begin{array}{l}\text { Severe } \\
\text { Preeclampsia } \\
(\mathrm{n}=23)\end{array}$ & $\mathrm{P}$ value \\
\hline Maternal age (years) & $23.62+2.98$ & $25.11+4.20$ & $25.70+4.35$ & \\
\hline Gestational age (weeks) & $37.18+3.05$ & $34.70+3.37$ & $34.96+3.11$ & \\
\hline $\begin{array}{l}\text { Blood Pressure }(\mathrm{mmHg}) \\
\text { Systolic } \\
\text { Diastolic }\end{array}$ & $\begin{array}{l}120.28+8.70 \\
80.20+5.88\end{array}$ & $\begin{array}{l}147.11+9.35 \\
100.22+8.84 \\
\end{array}$ & $\begin{array}{l}170.87+14.11 \\
106.52+11.12 \\
\end{array}$ & $* \mathrm{p}<0.001$ \\
\hline $\begin{array}{l}\text { Cases with proteinuria (n } \\
\begin{array}{ll}(\%) & \\
\text { - } & \text { Traces } \\
\text { - } & 1+ \\
\text { - } & 2+ \\
\text { - } & 3+\end{array}\end{array}$ & - & $\begin{array}{l}4(14.8) \\
16(59.3) \\
7(25.9) \\
-\end{array}$ & $\begin{array}{l}1(4.3) \\
3(13.0) \\
5(21.7) \\
14(60.9)\end{array}$ & \\
\hline Serum uric acid (mg/dl) & $4.53+1.30$ & $7.53+1.35$ & $8.16+1.57$ & $* \mathrm{p}<0.001$ \\
\hline Serum CRP (ug/ml) & 0 & $12.44+11.40$ & $14.35+13.98$ & $* \mathrm{p}<0.001$ \\
\hline
\end{tabular}


Table 2:-Plasma levels of elastase activity, $\alpha_{1}$-AT, $\alpha_{2}$-MG and NE- $\alpha_{1}$-ATcomplex in the study groups

\begin{tabular}{|l|l|l|l|l|}
\hline Parameters & $\begin{array}{l}\text { Normal } \\
\text { Pregnancy }(\mathrm{n}=50)\end{array}$ & $\begin{array}{l}\text { Mild Preeclampsia } \\
(\mathrm{n}=27)\end{array}$ & $\begin{array}{l}\text { Severe Preeclampsia } \\
(\mathrm{n}=23)\end{array}$ & P value \\
\hline $\begin{array}{l}\text { Plasma Elastase } \\
\text { Activity }(\mathrm{U} / \mathrm{ml})\end{array}$ & $0.40+0.10$ & $0.37+0.03$ & $0.70+0.08$ & $* \mathrm{p}<0.001$ \\
\hline Plasma $\alpha_{1}-\mathrm{AT}(\mathrm{mg} / \mathrm{dl})$ & $110.26+42.39$ & $83.94+25.08$ & $68.58+26.39$ & $* \mathrm{p}<0.001$ \\
\hline Plasma $\alpha_{2}-\mathrm{MG}(\mathrm{mg} / \mathrm{dl})$ & $265.37+66.91$ & $201.06+38.23$ & $298.79+32.52$ & $* \mathrm{p}<0.001$ \\
\hline $\begin{array}{l}* * \text { Plasma NE- } \alpha_{1}- \\
\text { ATcomplex }(\mathrm{ng} / \mathrm{ml})\end{array}$ & $171.08+23.81$ & $176.19+9.27$ & $164.31+11.63$ & $\mathrm{p}=0.285$ \\
\hline
\end{tabular}

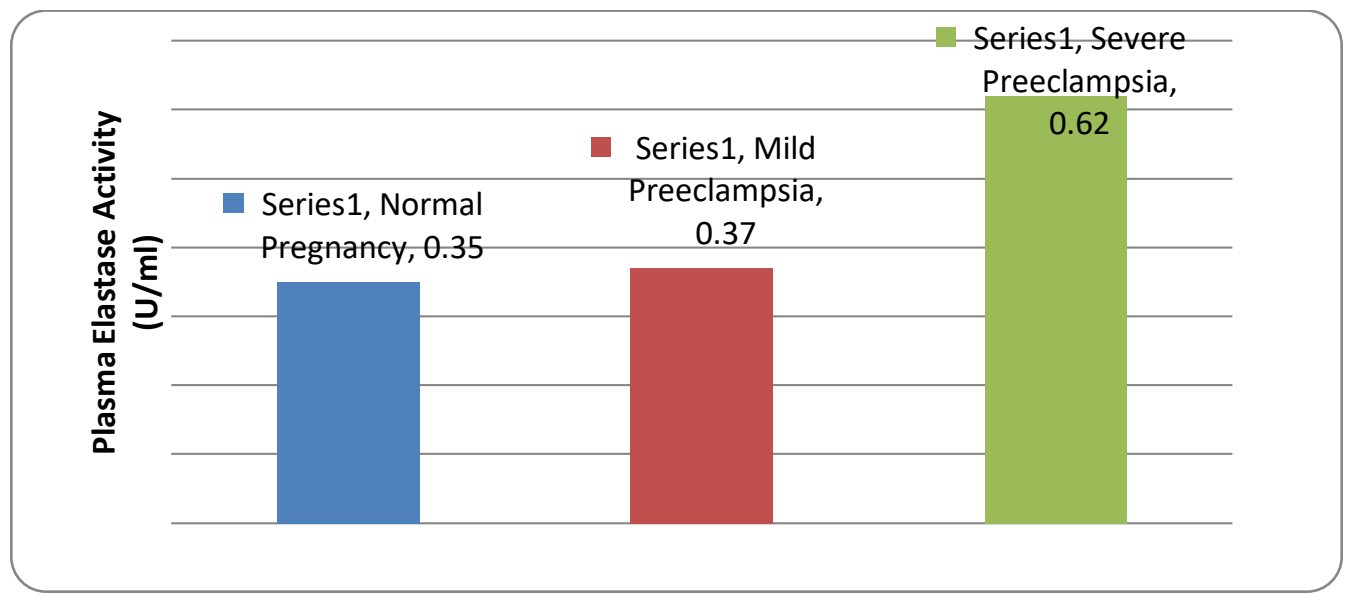

Fig 1:-Plasma elastase activity expressed in $\mathrm{U} / \mathrm{ml}$ of plasma in study groups.

\section{References:-}

1. Roberts JM, Taylor RN, Musci TJ, Rodgers GM, Hubel CA, McLaughlin MK. Preeclampsia: an endothelial cell disorder. Am J ObstetGynecol 1989; 161:1200-4.

2. Christianne A.R. Lok, JiskaJebbink, RienkNieuwland, Marijke M. Faas, Kees Boer, AuguesteSturk. Leukocyte Activation and Circulating Leukocyte-Derived Micro particles in Preeclampsia. American Journal of Reproductive Immunology 2009; 61:346-59.

3. A.M. Borzychowski, I. L. Sargent and C. W. Redman. Inflammation and Preeclampsia. Seminars in Fetal and Neonatal Medicine 2006; 11: 309-16.

4. F. Bernardi, F. Guolo, T. Bortolin, F. Petronilho and F. Dal-Pizzol. Oxidative stress and inflammatory markers in normal pregnanacy and preeclampsia. Journal of Obstetrics and gynecology Research 2008; 34: 948-51.

5. Pankaj Desai. Oxidative stress and obstetric vasculopathies. In: Pankaj Desai. Obstetric Vasculopathies. New Delhi: Jaypee Brothers Medical Publishers (P) Ltd, 2013: 69.

6. Luis Belo, Alice Santos- Silva, Susana Rocha, Muriel Caslake, Josephine Cooney, Luis Pereira-Leite et al. Fluctuations in C-reactive protein concentration and neutrophil activation during normal human pregnancy. European Journal of Obstetrics and Gynecology and Reproductive Biology. 2005; 123:46-51.

7. Cristina Catarino, Alice Santos- Silva, Luis Belo, Petronila Rocha-Pereira, Susana Rocha, Belmiro Patricio et al. Inflammatory disturbances in Preeclampsia: Relationship between maternal and Umbilical Cord Blood. Journal of Pregnancy. doi:10.1155/2012/684384.

8. Gupta Anurag kumar, GebhardtStefan, HillermannRenate, HolzgreveWolfganag, Hahn Sinuhe. Analysis of plasma elastase levels in early and late onset preelampsia. Archives of Gynecology and Obstetrics 2006; 273: $239-42$.

9. Felix Chua and Geoffrey J. Laurent. Neutrophil Elastase Mediator of Extracellular Matrix Destruction and Accumulation. The Proceedings of the American Thoracic society 2006; 3: 424-427.

10. Janoff A. Elastase in tissue injury. Annu Rev Med 1985; 36:207-16.

11. I.A.Greer, R. Leask, B.A. Hodson, J.Dawhs, D.C. Kilpatrick, W.A. Liston. Endothelin, elastase and endothelial dysfunction in preeclampsia. The Lancet 1991;558.

12. Edmund Lamb, David J.Newman and Christopher P.Price. Estimation of serum uric acid. In: Carl A Burtis, Edward R Ashwood and David E Bruns, editors. Teitz Textbook of Clinical Chemistry and Molecular Diagnostics. New Delhi: Elsevier Co, 2006:807. 
13. Bieth J, Spiess B, Wermuth CG. The synthesis and analytical use of a highly sensitive and convenient substrate of elastase. Biochemical Medicine 1974; 11: 350-57.

14. Belo L, Santos-Silva A, Caslake M, Cooney J, Pereira-Leite L, Quintanilha A et al. Neutrophil activation and C-reactive protein concentration in preeclampsia. Hypertens Pregnancy 200322:129-41

15. Halim A, Kanayama N, El Maradny E, Maehara K, Bhuiyan AB, Terao T. Correlated plasma elastase and sera cytotoxicity in preeclampsia. A possible role of endothelin -1 induced neutrophil activation in preeclampsia. Am J Hypertens 1996; 9:33-8.

16. A. Sharma, A. Satyam and J.B.Sharma. Leptin, IL-10 and inflammatory markers (TNF- $\alpha$, IL-6 and IL-8) in preeclamptic, normotensive pregnant and healthy non-pregnant women. American Journal of Reproductive Immunology 2007; 58: 21-30.

17. Keiko Fujie, Yasuhiko Shinguh, NoriakiInamura, RitsukoYasumitsu, Masanori Okamoto, MasakuniOkuhara. Release of neutrophil elastase and its role in tissue injury in acute inflammation: effect of the elastase inhibitor, FR134043. European Journal of Pharmacology 1999; 374(1): 117-25.

18. Petersen CM. Alpha 2-macroglobulin and pregnancy zone protein. Serum levels, alpha 2-macroglobulin receptors, cellular synthesis and aspects of function in relation to immunology. Dan Med Bull 1993; 40:409-46.

19. C. H. W. Horne, P.W. Howie and R.B. Goudie. Serum alpha2-macroglobulin, transferring, albumin and IgG levels in preeclampsia. J. Clin. Path 1970; 23: 514-6.

20. T. Sunitha, K. Sameera, G. Umaramani. Study of Biochemical changes in Preeclamptic Women. Int J Biol Med Res 2012; 3:2025-8.

21. FatemehMirzaie, FatemehRahimi-Shorbai and Amir HossianKazeronie. Association of maternal serum Creactive protein levels with severity of Preeclampsia. ActaMedicaIranica 2009; 47: 293-6.

22. K. Omkaramurthy, R Rathodvasantkumar, B.S.Dhanajaya, Sameena Sultana, U.N. Shobha. Pattern of Creactive protein in preeclampsia and normal pregnancy. International Journal of Biomedical and Medical Research 2012; 3: 2616-21. 